\title{
Editorial
}

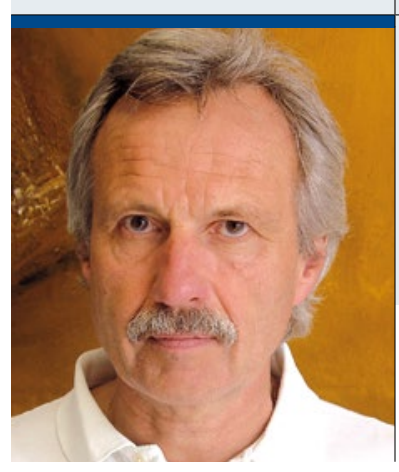

"Hat die Kostensenkungs- und Honorardebatte auch einmal die Präferenzen der Patienten dokumentiert?"

\section{Und Friede auf Erden!}

E in zu Weihnachten gern bemühter Ausspruch. Bezogen auf die lebensbedrohlichen, globalen kriegerischen Auseinandersetzungen ist das gerechtfertigt. Bezogen auf die Streitereien und Querelen im Gesundheitswesen scheint es etwas hoch gegriffen. Aber zwischen den Medizinern sowie im Kreis derer, die es werden wollen, gärt und brodelt es erheblich. Die Schlagzeilen der vergangenen Wochen und Monate suggerieren alles andere als Frieden und Verständnis.

Allen voran machen die Hausärzte mal wieder mobil und fühlen sich in ihrer hausärztlichen Kompetenz eingeschränkt. „Eine qualitativ hochwertige Primärversorgung kann ausschließlich von hierfür weitergebildeten Hausärzten sichergestellt werden“" posaunt der Verbandsguru Weigelt. Weg mit Überlegungen zu Gebietsfachärzten, grundversorgenden Fachärzten und erst recht Physician Assistants. „Ohne uns Hausärzte würden die Kosten explodieren und die Qualität in den Keller rauschen“. Eine „Frechheit“ sei die Idee der Hausarztrekrutierung für die Notfallambulanzen und für Dienste nach Ende der Sprechzeiten und an Wochenenden. Kann man verstehen! Man will ja schließlich nicht die Exazerbation dessen wiedersehen, was man die Woche über bebrütet hat. Das ist dann Facharztkompetenz. Nicht dagegen die Palliativversorgung. Die ist jedem Hausarzt in die Wiege gelegt. Daher wehrt man sich auch gegen jede Form eines Qualifikationsvorbehaltes. Das Bundesministerium für Gesundheit (BMG) sollte mal die Angemessenheit der Inhalte und Honorare überprüfen. Ist es pure Hybris oder sind es monetäre Kompetenzen, die Herrn Weigelt antreiben?

Bei den Apothekern soll das Rx-Versandhandelsverbot einen ruinösen Preiswettbewerb verhindern, sonst werde die flächendeckende, wohnortnahe Versorgung mit Medikamenten gefährdet. Definiere „ruinös“!?

Angestellte Ärzte in medizinischen Versorgungszentren (MVZ) beklagen Benachteiligungen und fordern eine Gleichbehandlung mit den Niederge- lassenen, insbesondere auf der Vergütungsebene. Die Honorarverhandlungen der Niedergelassenen für 2018 sorgen für die üblichen Streitereien. Der GKV-Spitzenverband lehnt sich pomadig zurück. Motto: Was juckt's den Mond, wenn der Hund nach ihm bellt. Die KBV keift gefrustet hilflos dagegen an. Der Vermittlungsausschuss gewährt gnädig knapp die Hälfte der KBV-Forderung. Das Spielchen hat Methode, wirkt erbärmlich und stellt die Machtverhältnisse klar.

Die Studenten klagen gegen den Numerus Clausus. Vor dem Hintergrund angeblich fehlender Mediziner erscheint das gerechtfertigt. Aber das wollen die Länder nicht wissen, denn Geld für mehr Studienplätze belastet die Länderkasse. Der „Masterplan Medizinstudium 2020“ erwähnt keine Studienplatzsteigerung.

Und wer streitet für Zeit, für Zuwendung bei der Betreuung der Kranken und für die Versorgung der Alten? Was ist, wenn der alte, gebrechliche Mensch der Demenz verfällt? Wer kann, soll, will die Pflege und Betreuung stemmen? Hat die Kostensenkungsund Honorardebatte einmal die Präferenzen der Patienten dokumentiert? Herr Weigelt will, dass sich das BMG um die Honorare der Hausärzte kümmert! Und was ist mit der Pflegereform? Was ist mit einer nicht nur monetären, sondern auch hierarchischen Aufwertung der Pflege? Demut und Barmherzigkeit stünde nicht nur in der „staden Zeit“ so manch stolzem Streiter gut zu Gesicht.

Frohe Weihnachten und ein gutes Neues Jahr! Ihr

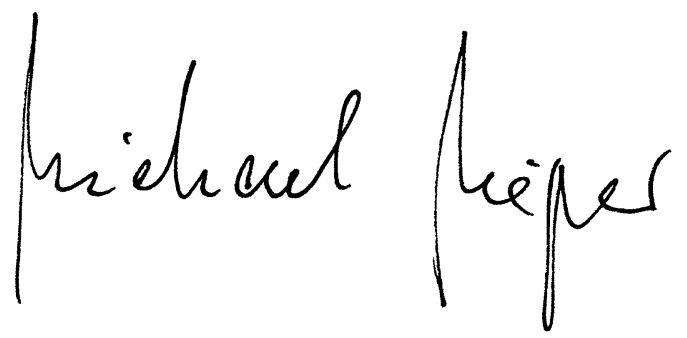

